\title{
Accounting
}

\section{Learning-by-doing effect: Evidence from firms of an emerging economy}

\author{
Nguyen Ngoc Thach ${ }^{a^{*}}$
}

\begin{abstract}
${ }^{a}$ Institute for Research Science and Banking Technology, Banking University HCMC, Vietnam

\begin{tabular}{l}
\hline C H R O N I C L E \\
\hline Article history: \\
Received March 102020 \\
Received in revised format March \\
152020 \\
Accepted May 302020 \\
Available online \\
June 52020 \\
\hline Keywords: \\
Bayesian mixed-effects regression \\
Firm specific learning-by-doing \\
Firm performance \\
Emerging economy
\end{tabular}

A B S T R A C T

In the learning theory, the vast majority of both theoretical and applied research have concentrated on the developed world. In contrast, developing, in particular, emerging economies have drawn much less attention. Moreover, empirical outcomes are conflicting, with some studies revealing learning-bydoing to have a positive impact, but others finding learning-by-doing to have a negative effect on the performance. Therefore, this study is conducted through the Metropolis-Hastings and Gibbs samplers in the context of a Cobb-Douglas specification to evaluate the effects of learning-by-doing on firm performance on a panel data of the 227 manufacturing firms listed on the Vietnamese stock market. A Bayesian mixed-effects regression used allows for capturing the varying effects of all the researched firms. The study found that firm-specific learning-by-doing has a strong positive influence on firm performance. This finding is accordant with the predictions of the learning theory, many previous investigations, as well as the fact that in a fast-growing economy like Vietnam, firm-specific learningby-doing is closely associated with economic growth. Some helpful policy implications proposed are aimed at increasing productivity for firms in emerging economies.
\end{abstract}

\section{Introduction}

As widely known, among the significant stylized facts on economic growth is the following: technical progress, education, and skills of the workforce play an increasingly crucial role in ensuring the high speed of economic growth. The importance of labor qualifications has been noted by the classics of economic theory, such as Adam Smith, Jean Baptiste Say, John Stuart Mills, Leon Walras, Arthur Pigou, and others. The concept of human capital was introduced in economics in the 1960's in the works of Jacob Mincer, Theodore Schultz, Gary Becker, and Mark Blaug. At an early stage of development of the growth theory, a focus was traditionally on only such economic factors as land, physical capital, and raw labor (the number of workers involved in production). Nowadays, human capital has become a primary determinant of economic growth. Human capital refers to a combination of professional knowledge and skills acquired in education and training programs, which subsequently may be profitable. In the modern growth theory, the mechanism of human capital accumulation is an essential part of endogenous growth models. The fundamental concepts of the effects of human capital and technical progress on the dynamics of economic systems go back to the works of Kenneth Arrow, Paul Romer, Hirofumi Uzawa, and Robert Lucas. The first concept of human capital was included in a classical article by Arrow (1962). In that work, increases in knowledge are "unintentional" through physical investment. That is a by-product of mechanization, or in other words, the mechanism of human capital accumulation is training in the process of work or on your own experience ("learning-by-doing"). This mechanism differs from that described

* Corresponding author

E-mail address: thachnn@buh.edu.vn (N. N. Thach) 
in Becker's theory and connected with an increase in employees' qualifications via paid education. Arrow associated the mechanism of human capital accumulation with physical investment by businesses or capital learning. In a broad meaning, however, learning-by-doing is also related to labor learning (or the learning of semi-manual and manual tasks) and organization learning. Research on labor learning has a long history starting with empirical analyses devoted to aircraft- and shipbuilding or another machine manufacturing (e.g., Wright, 1936; Montgomery, 1943; Alchian, 1950; Hirsch, 1952; Baloff, 1966). Later, learning-by-doing is examined as a productivity-enhancing determinant in a production specification (e.g., Rapping, 1965; Sheshinski, 1967). Organization learning, with its capacity to form organization capital, was analyzed by, among others, Conway \& Schultz (1959), Prescott \& Visscher (1980), Tomer (1981), Gort et al. (1985). Human capital accumulated through learningby-doing leads to an increase in labor productivity, which in turn fosters a rise of output. According to Killingsworth (1982), since the costs of learning-by-doing are less than those linked with the acquisition of knowledge through educational programs, older enterprises achieve superiority over beginners. In this case, the stock of knowledge and skills or experience accumulated in production activities is proxied by time elapsed from the enterprises' birth, i.e., firm age (e.g., Bahk \& Gort, 1993; Papatogonas, 2007; Coad et al., 2007; Akinomi \& Olagunja, 2012; Hui et al., 2013). As noted, the above analyzed theoretical and empirical works focus on firms or industries in developed economies. Few studies on learning-by-doing in the manufacturing firms of an emerging economy like Vietnam were carried out. Furthermore, Vietnam is still a specific economy in the process of economic transformation from plan to market, where the overwhelming majority of firms are comprised of newly established private and restructured state-owned ones. Moreover, distinct from previous studies conducted based on the frequentist approach, where the stock of knowledge, skills, or experience in production was specified as an independent variable in linear regression models, the present work will be aimed at accessing learning-by-doing within the context of a Cobb-Douglas specification based on a corporate dataset. For this goal, the research will employ the Bayesian mixed-effects regression. The application of Bayesian methods brings about some great advantages as highlighted in Section 3. Lastly, the inconsistency of different empirical results requires further consideration of the problem.

The remainder of the article is organized as follows. Analytical framework and empirical research are presented in the second section. The third section introduces research methodology, specifies the model, and describes the data sample. The fourth section provides Bayesian simulation results and discussions. The fifth section derives the conclusions of the study.

\section{Analytical Framework and Related Empirical Studies}

In his own learning-by-doing hypothesis, Arrow (1962) views the accumulation of knowledge (methods, skills, mastery, and other innovations applicable to production) as a byproduct of mechanization (represented by a capital-labor ratio). Maximizing long-term profit, firms make decisions on physical investment. Generating great production opportunities for firms in coming times, physical investment is restrained by the law of positive and diminishing productivities. Working environment alters with a new apparatus brought in. Operating it, workers learn the latest technology. More particularly, learning to use the new machine, the workers find out new forms of production organization and implement improvements upon it. That is, by increasing mechanization level, firms accumulate the knowledge stock via learning-by-doing process. Therefore, $A_{i t}$ grows by $\varphi$ percent each one percent increase in $K_{i t} / L_{i t}$ :

$$
A_{i t}=\omega\left(\frac{K_{i t}}{L_{i t}}\right)^{\varphi},
$$

where $A_{i t}$ represents the knowledge stock of firm $i=1,2, \ldots, N, \frac{K_{i t}}{L_{i t}}$ stands for its mechanization level, $\varphi$ denotes the learningby-doing elasticity of $A_{i t}$ relative to $\frac{K_{i t}}{L_{i t}}$ and positive, $\omega$ is a parameter. It is noteworthy that the learning-by-doing process cannot be perpetual; learning-by-doing effects will be gone over time. Let us notice that Arrow was not the first to invent learning-bydoing. Learning-by-doing has been a principle for millenniums; it was supported by numerous scholars, such as Plato, Thomas Hobbes, Karl Marx and Mao Zedong, English and Spanish epigrammatists, cultural anthropologists, Maria Montessori, Burrhus Skinner, and John Watson (Reese, 2011). Further, it is useful to distinguish labor learning-by-doing, capital learning-by-doing, and organization learning-by-doing. Concerning labor learning-by-doing, we agree with Bahk and Gort (1993) considering that the workforce's skills in specific assignments are obtained through experience. Repetition routinizes jobs and workers achieve better adaptation to their jobs. This kind of learning becomes more important in labor-intensive production activities (Hirsch, 1952; 1956; Hartley, 1965). Capital learning contains multiplying through experience engineering information about the level of mechanization, about the application of specialized instruments and devices, as well as about improvements in factory arrangement and the manipulation of materials. Organization learning may comprise the following essential components: First, the matching of workers and their duties relying on knowledge cumulated via the competencies and restrictions of workers; second, acquisition of interdependent understanding of production in some members' possession but not accessible to others in a group; third, the development of social capital as a combination of real or potential social resources related to maintaining 
trustful relationships among members of the organization; and last, managerial learning expressed in the development of coordination between divisions (Bahk \& Gort, 1993).

Additionally, we make the second distinction between firm-specific learning-by-doing and economy-wide or industry-wide learning-by-doing. Firm-specific learning is proprietary to firms with the returns not captured by labor, while returns to aggregate human capital, once acquired, are appropriated by employees and reflected in wage rates. In the current paper, we pay the main attention to firm-specific learning-by-doing. Here, economy-wide or industry-wide learning-by-doing as well as the effects of knowledge accumulation from the growth of human capital and the technical level embodied in physical capital are excluded from the analysis. Regarding firm-specific learning, growth economists perhaps know about "Horndal effect" (David, 1973; Lazonick \& Brush, 1985), i.e., verified by numerous empirical studies the effect of increasing productivity of workers and firms as the output of the same products grows under almost constant organizational and technological conditions. For example, labor productivity when manufacturing the aircraft body № N (counting them from the start of production) is approximately proportional to $N^{1 / 3}$. Graphical representation of the corresponding dependency (say, a relationship between the labor productivity of a representative worker and the number of units produced by a company) is called learning curve. Such dependency reflects labor learning. Since the research of Wright (1936) corresponding to the airframe industry, learning-bydoing has been analyzed through a progress function determining variations in production costs through the years. Together with the work of Montgomery (1943) relative to shipbuilding, Alchian (1950) investigated aircraft. Besides, Hirsch (1952) and Baloff (1966) analyzed machine manufacturing, while Preston and Keachie (1964) studied radar equipment, or Lieberman (1984) - chemical products. All the mentioned works are considered classical in this strand. Specifically, in Rapping (1965), Sheshinski (1967), learning-by-doing is first referred to as a productivity-enhancing factor in a production function. The link between company age and entrepreneurial performance has become a topic of diverse conceptual research, not only the learning theory but also the liability of obsolescence and liability of senescence theories. From the learning theory, it is logical to expect that there exists a positive relationship between firm age and business performance. This is because as firms exist longer, they gain more experience and become more productive than newcomers. Contrary to the learning-by-doing hypothesis, the liability of obsolescence theory indicates a mismatch between company targets and the business environment, whereas the liability of senescence concept points out internal inefficiency resulting from age (Hannan \& Carrol, 1992). A lot of empirical analyses have been performed against the backdrop of the mentioned theories. It turns out that the correlation between company age and entrepreneurial performance is contentious. While some studies found that firm age is positively connected with entrepreneurial performance (e.g., Bahk \& Gort, 1993; Papadogonas, 2007; Rosli, 2011; Halil \& Hasan, 2012; John et al., 2012), others revealed a negative correlation (e.g., Gardner, 1965; Majumdar, 1997; Dogan, 2013; Pervan et al., 2016). A negative linkage between company age and profitability was shown by Gardner (1965). Majumdar (1997) examined the effects of age and size on entrepreneurial performance on a dataset of 1020 Indian companies. The empirical result showed that Indian older companies work more productively. Relying on a sample of 200 firms listed on the Istanbul Stock Exchange between 2008 and 2011, Dogan (2013) revealed a negative relationship between age and profitability. Pervan et al. (2016) affirmed that as companies become older, benefits from their experience in all primary activities of business were overwhelmed by the inertia and osseous caused by the accumulation of routines, organizational structure, and rules. On the contrary, among others, Bahk \& Gort (1993), Garnsey (1998), Kristiansen et al. (2003), Harvie et al. (2010), Rosli (2011), Cowling et al. (2012), and Okunbo \& Oghuvwu (2019) yielded the opposite results. Bahk \& Gort (1993) discovered a positive relationship between firm age and entrepreneurial performance on the data set of plants in 41 U.S. manufacturing industries. Kristiansen et al. (2003) asserted that firm age is associated with business performance for Indonesian businesses because entrepreneurs from older firms have more experience and are very independent. Harvie et al. (2010) (for ASEAN small and medium enterprises), Rosli (2011) (for Malaysian firms) established that firm age greatly impacts on entrepreneurial performance. Cowling et al. (2012) investigated the relationship between firm age and performance for UK companies and revealed that firm age is positively significant to firm performance. Okunbo \& Oghuvwu (2019), based on Small and Medium Enterprise Development Agency of Nigeria Survey, affirmed a positive impact of firm age on the performance of a hundred small and medium business entrepreneurs from the wholesale, retail, and manufacturing sector. Nonetheless, Coad et al. (2007), applying various estimation techniques (LAD, OLS, and VAR) to a panel of Spanish manufacturing firms for 1998-2006, found the conflicting evidence, on the one hand, better performance of enterprises with age and, on the other hand, reduction of their productivity with age. In sum, the aforementioned mixed results have induced an inconclusive debate. The controversy over the firm age-performance relationship is one of the main factors encouraging us to carry out this research.

\section{Research Method and Data}

\subsection{Method and Model Specification}

Bayesian statistical methods have been becoming ever more popular in social and behavioral science research over the last three decades while using the p-value to test hypotheses has confronted severe criticism. According to many studies (see, e.g., Hung \& Thach, 2018; Anh et al., 2018; Hung \& Thach, 2019; Hung et al., 2019a; Hung et al., 2019b; Sriboonchitta et al., 2019; Svítek et al., 2019; Kreinovich et al., 2019; Thach et al., 2020; Thach, 2020a; Thach, 2020b), Bayesian methods have the advantages 
over the standard frequentist approach. First, universality is the great superiority of the Bayesian methods because the Bayes rule can be applied to all regression models, whereas a frequentist method is often appropriate only for one model class, but not for different classes. Second, contrast to frequentist inference, the Bayesian approach provides a straightforward and intuitive probabilistic interpretation of results. Bayesian inference using noninformative priors and frequentist inference produce similar results, but their interpretations differ in probabilistic sense. For instance, $95 \%$ confidence intervals mean that, if we repeat the same experiment many times, then the confidence intervals of $95 \%$ of the experiments will contain a population parameter of interest. But in Bayesian analysis, 95\% credible intervals allow for making a probability statement that the true value of a particular parameter falls into a prespecified interval with a probability of $95 \%$. Third, Bayesian result is an entire posterior distribution, while frequentist inference yields point estimates derived from a likelihood function. In Bayesian modeling, there is no need for the application of any approximation to evaluate uncertainties as the entire posterior distribution of the parameter is at hand. For the above reasons, we access a Bayesian approach via the Metropolis-Hasting and Gibbs samplers as the MCMC methods to estimate the firm-specific learning-by-doing effects on firm performance in this work. We begin our Bayesian analysis with forming a posterior distribution that encompasses two sources of information: out-of-data, prior belief, and information concluded in data:

Posterior $\propto$ prior $\times$ likelihood,

where Eq. (2) is called Bayes' theorem, which is mathematically defined as:

$$
P(A \mid B)=\frac{P(B \mid A) P(A)}{P(B)},
$$

where with events $A$ and $B, P(A \mid B)$ denotes the conditional probability that event $A$ takes place given the occurrence of event $B$, $(P(B \mid A)$ is also the conditional probability, but the roles of $A$ and $B$ are reversed, $P(A)$ and $P(B)$ are the marginal probabilities of occurrence of event $A$ and event $B$ respectively. The flexibility of Bayesian analysis is that Bayes' theorem allows for involving prior beliefs in the model. Prior choice is crucial in Bayesian analysis as priors affect posterior distribution. While Yang \& Berger (1998) support objectivity, several other researchers (e.g., Gelman \& Hill, 2007; Kruschke, 2010; German et al., 2013; Hobbs \& Hooten, 2015; Lemoine, 2019) favor a middle perspective, according to which weakly informative priors should include sufficient information to regularize estimates: the priors should rule out unreasonable values of a parameter but need not be so strong as to rule out its meaningful values. In the current research, we advocate the middle perspective, accounting for its capability of providing more unbiased and robust estimation results. Therefore, prior choice is proposed as follows:

- As we have a sufficiently big sample size of 227 firms for 11 years, the likelihood can overwhelm the information included in the priors. In Bahk \& Gort (1993), the coefficient for the learning-by-doing variable is positive. In the meanwhile, others (e.g., Gardner, 1965; Majumdar, 1997; Dogan, 2013) found that the firm age-performance relationship is inconsistent. So, we select a normal prior on the coefficient for variable learning-by-doing with the zero mean such that the Bayesian results concerning our hypotheses in either positive or negative direction will not be biased. Using the sensitivity analysis proposed by Korner-Nievergelt et al. (2015), we rerun a Bayesian inference with progressively narrower prior distributions. Following Block et al. (2011), we set an error variance of 1 and to vary the mean in a range from -0.5 to 0.5 in order to examine sensitivity on posterior distributions to prior choice. 11 simulations are performed accordingly (see the simulation results in Table 4).

- For the case of elasticities in a neoclassical production function, priors are expected to be between 0 and 1 . So, prior uniform $(0,1)$ is appropriate. If we, however, want to ease restraints, then $\mathrm{N}(0.5,0.5)$ is a reasonable choice too. Referring to Thach (2020b), we select the uniform prior.

In agreement with Rapping (1965), Sheshinski (1967), to estimate learning-by-doing effect, we regard learning-by-doing as a productivity-enhancing factor in a Cobb-Douglas function, where firm-specific learning-by-doing is simply modeled as a separate argument. In our case, firm-specific learning-by-doing and the Solow residual are considered the sources of disembodied technical change. The Solow residual represents Hicks-neutral technical change. Such that a multiplicative productivity term $\mathrm{A}(\mathrm{t})$ is involved in our Cobb-Douglas function (see Function 4 below), which captures the residual proportion of output augmentation that emerges from aggregate learning-by-doing and other qualitative changes, except for firm-specific learning-by-doing. Applying the Cobb-Douglas specification to our panel data, we obtain:

$$
Q_{i t}=A(t) E_{i t}^{\beta} K_{i t}^{\alpha} L_{i t}^{1-\alpha},
$$


where $Q$ denotes output, $K$ denotes physical capital, $L$ denotes labor, $A$ is Hicks-neutral technical change, $E$ is learning-by-doing (experience), the subscripts $i$ and $t$ are firm and period, respectively. Furthermore, Eq. (4) is expressed in its econometric specification:

$$
\ln Q_{i t}=b 0+\beta E_{i t}+\alpha \ln K_{i t}+(1-\alpha) \ln L_{i t}+\varepsilon_{i t},
$$

where $Q$ is output proxied by net revenue, $L$ is labor proxied by the number of employees, $K$ is stock of physical capital, $E$ is learning-by-doing proxied by firm age. Hence, our Bayesian mixed-effects model is specified as follows:

Likelihood:

$$
\ln Q_{i t}=b_{0}+\beta \operatorname{lnage}_{i t}+\alpha \ln k 2010_{i t}+(1-\alpha) \ln l_{i t}+u_{1 t}+\varepsilon_{i t} .
$$

Priors:

$$
\begin{array}{lcc}
b_{0} \sim N(0,100), & \beta \sim \operatorname{normal}(0,1) & \alpha \sim \text { uniform }(0,1) \\
u_{1 t} \sim N\left(0, \sigma_{i d}^{2}\right) & \sigma_{0}^{2} \sim \operatorname{Igamma}(0.001,0.001) & \sigma_{i d}^{2} \sim \operatorname{Igamma}(0.001,0.001)
\end{array}
$$

where $\ln k 2010, \ln l, \ln Q$ refer to, respectively, natural $\log$ of capital, labor, output at constant prices, $b_{0}$ denotes efficiency parameter, $\alpha$ denotes income share of capital, $\varepsilon_{i j}$ is random error, $u_{1 t}$ is random effects, year $t=2008, \ldots, 2018$, and enterprise $i=1,2,3, \ldots, 227$. Note that Cobb-Douglas specifications are popularized in empirical growth literature, especially regarding growth decomposition problems. Besides, Bayesian mixed-effects models are useful for the analysis of individual impacts of firms on the model outcome thanks to the grouping structure of data, where multiple levels of nested groups encompass both random effects and fixed effects. The two-level mixed-effects models account for variability among firms identified by the variable id. As emphasized by Nezlek (2008), if the multilevel nature of data is not taken into account, the results of multilevel data analysis may not be accurate.

\subsection{Data Description}

The present work utilized a firm-level panel of the 227 manufacturing firms listed on the Vietnamese stock market between 2008 and 2018. The data sources are the annual financial statements and annual reports of the studied firms for the relevant years. According to Ilaboya \& Ohiokha (2016), "the choice of panel data approach is premised on the fact that it provides larger data points, increase the degree of freedom and reduces the problem of collinearity of the explanatory variables." The firms in the research sample operate in a variety of manufacturing industries, and hence, their varying effects on the outcome are captured through a mixed-effects regression. The data has a frequency of years. The dataset consists of 1,974 observations. Firm capital and output are represented by fixed assets and net revenue recalculated on the 2010 producer price index (Vietnam General Statistics Office, 2019). Labor is represented by the number of employees, age is represented by the number of years from a firm's foundation. The manufacturing firms are selected for analysis, for they are a driving force of Vietnamese economic growth. The application of a dataset on the listed companies enables labor and capital shares not to be biased because of statistical errors often occurring as mixed incomes from the households' labor and capital contributions, and those in the public sector are hardly measured correctly (Karabarbounis \& Neiman, 2014). Owing to the skewed distributions of the variables, we log age,

\begin{tabular}{|c|c|c|c|c|}
\hline Variable & & Notation & Measurement & Data Source \\
\hline \multirow[b]{2}{*}{ Input } & Labor & $\ln 1$ & Natural logarithm (number of employees) & Firms' annual report \\
\hline & Capital & $\operatorname{lnk} 2010$ & $\begin{array}{l}\text { Natural logarithm (net fixed assets/Producer price } \\
\text { index) }\end{array}$ & Firms' financial statement \\
\hline Output & Product & $\ln Q$ & Natural logarithm (net revenue/Producer price index) & Firms' financial statement \\
\hline Learning-by-doing & Firm age & lnage & $\begin{array}{l}\text { Natural logarithm (number of years from firm } \\
\text { establishment) }\end{array}$ & Firms' annual report \\
\hline PPI & Producer price index & PPI & 2010 as a base year & $\begin{array}{l}\text { Vietnam General Statistics } \\
\text { Office }\end{array}$ \\
\hline
\end{tabular}
output, capital, and labor in our regression model. Table 1 provides the measurements of the research variables, most of which were used by Thach (2020a).

Table 1

Measurements of research variables 


\section{Regression Results}

\subsection{Bayesian Posterior Simulations}

In Bayesian analysis, acceptance rate and efficiency are practiced to judge the efficiency of MCMC estimators, which influences MCMC convergence. Rate of acceptance, by definition, is the fraction of accepted proposals in the total proposals, whereas efficiency indicates how well Markov chains mix. Bayesian information criteria show that the specified simulations get the almost same DIC estimates. Therefore, we choose simulation 3 having the lowest DIC value for further analysis as a typical illustration. The Bayesian results for simulation 3 report that this model reaches an acceptance rate of 0.58 . The smallest, average, and largest efficiency reported is equal to $0.04,0.47$, and 1 , respectively and all these initial indicators higher than the warning rate of 0.01 . These levels can be accepted, according to Roberts and Rosenthal (2001). Most posterior means of the parameters, as well as random effects, obtain reasonable Markov chain standard errors (MCSEs) of less than one tenths (Tables 2 and 3). In general, the lower the MCSE estimates, the more precise the posterior mean values of the parameters. Moreover, the Bayesian approach provides a straightforward and intuitive probabilistic interpretation for credible intervals. For instance, in our model, a Bayesian credible interval [0.33, 0.39] is interpreted as the interval, which parameter alpha (capital share) belongs to with a probability of $95 \%$ (Table 2 ).

Table 2

Bayesian posterior simulations

\begin{tabular}{|c|c|c|c|c|c|c|}
\hline Parameter & Mean coefficient & Std. Dev & MCSE & $\begin{array}{c}\text { Posterior } \\
\text { probability of } \\
\text { coefficient }>0\end{array}$ & \multicolumn{2}{|c|}{$\begin{array}{c}\text { Equal-tailed } \\
{[95 \% \text { Cred. Interval] }}\end{array}$} \\
\hline Natural $\log$ (capital)* & .3633044 & .0145531 & .000981 & 1 & .3333752 & .3924041 \\
\hline Natural $\log (\mathrm{A})$ & 3.811807 & .1230542 & .010694 & 1 & 3.582262 & 4.060153 \\
\hline Natural log (learning-by-doing) & .3766484 & .032601 & .002449 & 1 & .3120829 & .4379703 \\
\hline Overall uncertainty & .1233717 & .0042337 & 000077 & 1 & .1154946 & 131996 \\
\hline Random intercepts uncertainty & .6361844 & .0637335 & .001718 & 1 & .5257349 & .7706273 \\
\hline
\end{tabular}

Note: * Posterior probability of the coefficient of $\log$ (capital) in the interval $(0,1)$ is $100 \%$.

Source: The author's computations

Also, regarding simulation 3 , random intercepts for $u_{1 t}$ (id) imply variations in the individual effects of the researched firms on the outcome of the model. All the random effects achieve the sufficiently low MCSE estimates for MCMC methods, which point at the highly efficient MCMC simulations. For illustration, the first 20 firms' estimates of the random intercepts are presented in Table 3.

Table 3

Posterior simulations of random intercepts of 20 firms

\begin{tabular}{|c|c|c|c|c|c|c|}
\hline & \multirow{2}{*}{ Mean } & \multirow{2}{*}{ Std. Dev. } & \multirow{2}{*}{ MCSE } & \multirow{2}{*}{ Median } & \multicolumn{2}{|c|}{ Equal-tailed } \\
\hline & & & & & [95\% Cred. & Interval] \\
\hline \multirow{2}{*}{\multicolumn{7}{|c|}{$\ln y 2010$}} \\
\hline & & & & & & \\
\hline & -.0402059 & .1326178 & .003383 & -.0374557 & -.2945865 & .2189321 \\
\hline & -.3829814 & .1174514 & .003303 & -.3845203 & -.6076356 & -.1537845 \\
\hline & -.4448979 & .1207932 & .003663 & -.4437505 & -.6856812 & -.2151446 \\
\hline & .6781612 & .1288561 & .005238 & .6793082 & .4262275 & .926714 \\
\hline & -.1586318 & .1178592 & .00341 & -.1614853 & -.3887248 & .073654 \\
\hline & .4433483 & .1794721 & .003986 & .4461544 & .0829891 & .7815247 \\
\hline & -.3071653 & .1283132 & .003394 & -.3075616 & -.5532817 & -.0564984 \\
\hline & 1.311922 & .1214479 & .003397 & 1.311191 & 1.06827 & 1.551771 \\
\hline & -.8049211 & .1211782 & .002972 & -.8044031 & -1.046562 & -.5698457 \\
\hline 1 & -.5708233 & .1255111 & .003104 & -.5741194 & -.8086729 & -.3199843 \\
\hline 1 & .3522455 & .1427323 & .00381 & .3551475 & .0740645 & .6296982 \\
\hline 1 & .7002935 & .1231915 & .003032 & .7009352 & .4661121 & .9409311 \\
\hline 1 & -.4279527 & .1166162 & .003137 & -.4314988 & -.6504045 & -.1977667 \\
\hline 1 & .1397481 & .1409215 & .003336 & .1388848 & -.1382145 & .41616 \\
\hline 1 & -.4638785 & .1427042 & .003171 & -.4680294 & -.7387795 & -.1769516 \\
\hline 1 & 1.236439 & .1838869 & .004171 & 1.231219 & .8793809 & 1.607156 \\
\hline 1 & -.0695661 & .1575895 & .005722 & -.0719153 & -.3749977 & .2421988 \\
\hline 1 & -.5634294 & .1336612 & .003302 & -.5631914 & -.8312518 & -.3064052 \\
\hline 1 & .7355271 & .1158373 & .002889 & .7373313 & .507306 & .9615617 \\
\hline 2 & .4880821 & .139683 & .003646 & .4897209 & .2157439 & .756033 \\
\hline
\end{tabular}

Source: The author's computations 
Importantly, the posterior distributions, which are not sensitive to various prior choices, indicate a sign of model robustness. This is proven by the results recorded in Table 4, where there are inconsiderable differences between summaries of posterior distributions, posterior means, their MCSEs, and credible intervals of the learning-by-doing variable when the mean of the normal prior is adjusted step-by-step from -0.5 to 0.5 with even spacing of 0.1 .

\section{Table 4}

Sensitivity analysis with respect to prior choice

\begin{tabular}{|c|c|c|c|c|c|c|c|c|c|c|c|c|}
\hline \multirow{2}{*}{$\begin{array}{l}\text { Variable } \\
\text { of interest }\end{array}$} & \multirow{2}{*}{$\begin{array}{l}\text { Summaries } \\
\text { of posterior } \\
\text { distributions }\end{array}$} & \multicolumn{11}{|c|}{ Mean of prior distributions } \\
\hline & & -0.5 & -0.4 & -0.3 & -0.2 & -0.1 & 0 & 0.1 & 0.2 & 0.3 & 0.4 & 0.5 \\
\hline \multirow[t]{3}{*}{$\begin{array}{l}\text { Learning- } \\
\text { by-doing }\end{array}$} & $\begin{array}{l}\text { Mean } \\
\text { coefficient }\end{array}$ & .374 & .373 & .377 & .375 & .374 & .375 & .375 & .375 & .375 & .370 & .352 \\
\hline & $\begin{array}{l}\text { Standard } \\
\text { deviation }\end{array}$ & .033 & .035 & .033 & .033 & .032 & .035 & .035 & .035 & .035 & .034 & .034 \\
\hline & $\begin{array}{l}\text { MCSE } \\
\text { Credible } \\
\text { interval }\end{array}$ & $\begin{array}{l}.003 \\
{[.313} \\
.441]\end{array}$ & $\begin{array}{l}.004 \\
{[.307} \\
.441]\end{array}$ & $\begin{array}{l}.002 \\
{[.312} \\
.438]\end{array}$ & $\begin{array}{l}.003 \\
{[.310} \\
.442]\end{array}$ & $\begin{array}{l}.003 \\
{[.312} \\
.437]\end{array}$ & $\begin{array}{l}.003 \\
{[.308,} \\
.449]\end{array}$ & $\begin{array}{r}.003 \\
{[.308,} \\
.449]\end{array}$ & $\begin{array}{l}.003 \\
{[.308} \\
.449]\end{array}$ & $\begin{array}{l}.003 \\
{[.308} \\
.449]\end{array}$ & $\begin{array}{l}.003 \\
{[.306} \\
.438]\end{array}$ & $\begin{array}{l}.003 \\
{[.285} \\
.417]\end{array}$ \\
\hline
\end{tabular}

Source: The author's computations

As analyzed in the above, simulation 3 is acceptable for inference. Before proceeding to inference, we should verify whether MCMC chains have converged to a stationary regime. The ideal Monte Carlo algorithm employs independent successive random values. In the application of MCMC samplers, successive draws are not independent, which makes the methods converge slower than the ideal Monte Carlo. The faster they mix, the faster the dependence decays in successive iterations, and the faster they converge. The successive draws are rapidly "almost independent" of the initial state. We are motivated for well mixing chains as we are wary about time consuming and, more importantly, we desire a representative sample from the marginal posterior distribution. The former are dependent on the complexity of the model: if the model is simple, it may not matter much whether our algorithm is efficient. The latter is very significant if we are interested in posterior uncertainty or acquiring posterior means with high precision. The chain convergence to the desired distribution enables us to conclude that Bayesian iterations produce consistent estimations once the model has achieved validity. In Bayesian analysis, two conventional diagnostic techniques of convergence most often practiced are formal and graphical. We apply cusum lines and effective sample size in this research. Fig. 1 graphically describes the properties of MCMC convergence for simulation 3 . For all the model parameters, their diagnostic graphs are reasonable in terms of convergence because the cusum lines are jagged, but not smooth, which definitely indicates the convergence of Markov sequences.

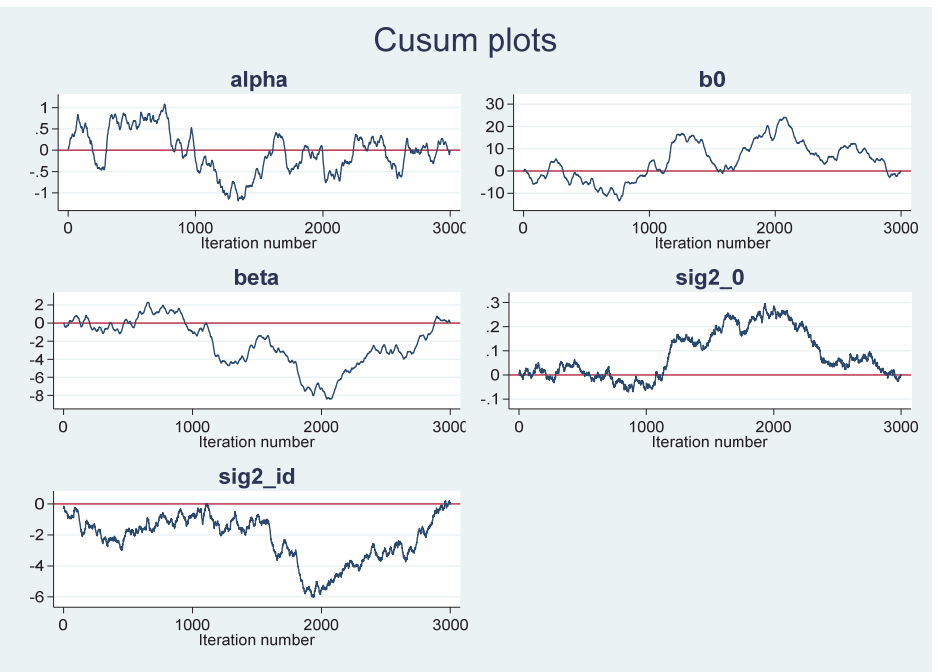

Fig. 1. Visual diagnosis of MCMC convergence Source: The author's computations

In addition to the graphical inspection, we can monitor effective sample size for checking MCMC convergence. Because of an efficiency estimate of more than 0.01 , we acquire a satisfactory result. According to the estimation results, the efficiency of all the parameters is higher than this level.

In sum, chain mixing looks convincing and our Bayesian simulations tackle no convergence problems. 


\subsection{Discussion}

In the present research, relying on the middle view to specify suitable priors, we could increase model robustness. Accordingly, weakly informative priors were included in our Bayesian regression model to regularize parameter estimates and stabilize posteriors. Regularization priors allows for reducing or avoiding common errors corresponding to noninformative or frequentist analyses. Based on the results of the sensitivity analysis (Table 4), we can affirm that prior choice has a minimal effect on the posterior inference and thus, our specified model is valid. In addition, visual and formal checks for the chain convergence ensure our conclusion about model robustness. Moreover, concerning all our simulations, the standard deviation of all the parameters is small, while all the MCSE values are less than one decimal position. These are sufficient for the preciseness of the posterior means. It follows that our model can be employed for further inference. As claimed before, a substantial advantage of the Bayesian approach is to allow for probability statements what a standard frequentist framework cannot do. In our case, the summaries reported in Table 2 permit a statement that the probability of a positive impact of the predictor variable learning-bydoing as well as the remaining variables on the response variable output is $100 \%$; the coefficient for the learning-by-doing variable belongs to the interval $[0.31,0.44]$ with a probability of about $95 \%$; capital share falls into the interval $[0,1]$ with a $100 \%$ probability. Importantly, the Bayesian simulation results demonstrate that because no credible intervals contain the zero value (Table 2), variable lnage (firm-specific learning-by-doing) correlates positively and strongly with variable $\ln Q$ (output). In other words, firm-specific learning-by-doing has a positive and strong effect on firm performance. It means that without any doubt, the firms become more productive with their age. This finding, which is in line with many earlier studies (see, among others, Gardner, 1965; Majumdar, 1997; Dogan, 2013; Okunbo \& Oghuvwu, 2019), shows that the learning-by-doing hypothesis is accordant with the Vietnamese manufacturing firms. A probable explanation is that the majority of Vietnamese businesses are in nascent stages, which is a common feature of emerging economies. In a fast-growing economy like Vietnam, firms achieve a coincident increase in learning-by-doing and performance. In such a dynamic business environment, firms must manage to achieve rapid advancements, from immaturity to vitality and flexibility, from a lack of experience to learning capability, from external financing to accumulation of internal resources, and from institutional uncertainty and opacity to an established settlement. Besides, the Vietnamese state-owned enterprises should effectively restructure themselves to develop further in a market-oriented economy. And what's more, as indicated by the simulation results, the labor share equals roughly 0.64 (Table 4). This finding seems paradoxical for a capital-intensive manufacturing sector in an emerging economy. A probable explanation is that the contribution of human capital embodied in labor may not be accounted for in our model. This omission is considered a main limitation of our study.

\section{Conclusion}

Learning-by-doing effect is recognized to exist in the production processes of firms from ancient times to nowadays. Nevertheless, conflicting empirical findings cause a continuing controversy, which motivates us to conduct the current research. Specifically, few studies on learning-by-doing effects are dedicated to emerging countries. By utilizing a panel data of the 227 manufacturing firms listed on the Vietnamese stock market, the study employed the Bayesian mixed-effects regression in the context of a Cobb-Douglas production function to access the impact of firm-specific learning-by-doing on their firm performance, where individual effects of the studied firms on the model outcome are taken into account. Cobb-Douglas specifications are most relevant to the analysis of growth problems. In our Cobb-Douglas framework, beside the disembodied Hicks-neutral technical change, the learning-by-doing variable enters the production function as a separate predictor. Such settings enable the model to capture the distinct impact of firm-specific learning-by-doing on firm performance. Along with a sensitivity analysis, the MCMC convergence tests performed confirm that our Bayesian simulations are robust. According to the posterior simulation results, firm-specific learning-by-doing measured by company age positively and strongly affects firm performance. Our findings are consistent with the learning-by-doing hypothesis and many empirical investigations finding a positive relationship. The fact that the learning-by-doing effects exist in the Vietnamese manufacturing firms is obvious. This is because the Vietnamese economy has been growing rapidly in recent decades, which stimulates the development of the firms, encouraging them to raise productivity. Based on the empirical results obtained, the study recommends the Vietnamese firms to enhance productivity growth through motivating workers to accumulate human capital in many ways, including learning-bydoing in all its forms. Additionally, there is an essential need to foster the restructuring of the state-owned enterprises. In this regard, the state has to keep in its ownership only economically or socially important enterprises. Moreover, to increase the effectiveness of the firms, it is crucial to improve the institutional quality and to create an environment of fair competition. Last but not least, as medium and small firms account for more than $90 \%$ of businesses in Vietnam, the state should increase access to credit for this group of firms. All the above mentioned measures are aimed, in general, at enhancing firm productivity. Notably, policy implications suggested for the Vietnamese firms may be adopted by firms from other emerging economies.

\section{References}

Anh, L.H., Kreinovich V., \& Thach N.N. (2018). Econometrics for Financial Applications. Cham: Springer. 
Alchian, A. (1963). Reliability of progress curves in airframe production. Econometrica: Journal of the Econometric Society, 31(4), 679-693.

Arrow, K. J. (1962). The Economic Implications of Learning-by-doing. Review of Economic Studies, $29,155-173$.

Bahk, B. H. \& Gort, M (1993). Decomposing learning-by-doing in new plants. Journal of Political Economy, 101(4), 561-583.

Baloff, N. (1966). Startups in machine-intensive production systems. Journal of Industrial Engineering, 17(1), 25.

Block, J. H., Jaskiewicz, P., \& Miller, D. (2011). Ownership versus management effects on performance in family and founder companies: A Bayesian reconciliation. Journal of Family Business Strategy, 2(4), 232-245.

Coad, A., Segarra, A., \& Teruel, M. (2013). Like milk or wine: Does firm performance improve with age?. Structural Change and Economic Dynamics, 24, 173-189.

Conway, R. W., \& Schultz, Andrew, Jr. (1959). The Manufacturing Progress Function. Journal of Industrial Engineering, 10, 39-53.

Cowling, M., Liu, W., \& Ledger, A. (2012). Small business financing in the UK before and after the financial crisis. International Small Business Journal, 30(7), 778-800.

David P.A. (1973). The «Horndal effect» in Lowell, 1834-1856: A short-run learning curve for integrated cotton textile mills. Explorations in Economic History, 10(2), 131-150.

Dogan, M. (2013). Does firm size affect the firm profitability: Evidence from Turkey data of 200 companies active in the Instanbul Stock Exchange between 2008-2011. Research Journal of Finance and Accounting, 4(4), 53-59.

Gardner, J. W. (1965). How to prevent organizational dry rot. Rice Thresher, 53(5).

Garnsey, E. (1998). A theory of the early growth of the firm. Industrial and Corporate Change, 7(3), 523-556.

Gelman, A. \& Hill, J. (2007). Data analysis using regression and multilevel/hierarchical models. Cambridge Univ. Press.

Gort, M., Grabowski, H., \& McGuckin, R. (1985). Organizational capital and the choice between specialization and diversification. Managerial and Decision Economics, 6(1), 2-10.

Halil, E. A., \& Hasan, A. K. (2012). The effect of firm size on profitability: An empirical Icelandic firms. Bifröst Journal of Social Science, 1, 33-42.

Reese, H. W. (2011). The learning-by-doing principle. Behavioral development bulletin, 17(1), 1.

Hannan, M. T., \& Carroll, G. R. (1992). Dynamics of organizational populations: Density, legitimation, and competition. Oxford University Press.

Hartley, K. (1965). The learning curve and its application to the aircraft industry. The Journal of Industrial Economics, 13(2), 122-128.

Harvie, C., Narjoko, D., \& Oum, S. (2010). Firm characteristic determinants of SME participation in production networks. ERIA discussion paper series, 11, 1-52.

Hirsch, W. Z. (1952). Manufacturing progress functions. The Review of Economics and Statistics, 34(2), $143-155$.

Hirsch, W. Z. (1956). Firm progress ratios. Econometrica, Journal of the Econometric Society, 24(2), $136-143$.

Hobbs, N. T., \& Hooten, M. B. (2015). Bayesian models: a statistical primer for ecologists. Princeton University Press.

Hui, H., Wan Mohamed Radzi, C. W. J., Salarzadeh Jenatabadi, H., Abu Kasim, F., \& Radu, S. (2013). Influence of organizational learning and innovation on organizational performance in Asian manufacturing food industry. Asian Journal of Empirical Research, 3(8), 962-971.

Nguyen, H. T., \& Thach, N. N. (2018). A Panorama of Applied Mathematical Problems in Economics. Thai Journal of Mathematics, 1-20.

Hung, T. N. \& Thach, N.N. (2019). A Closer Look at the Modeling of Economics Data. In: Kreinovich V., Thach N., Trung N., Van Thanh D. (eds) Beyond Traditional Probabilistic Methods in Economics. ECONVN 2019. Studies in Computational Intelligence, vol 809. Springer, Cham. https://doi.org/10.1007/978-3-030-04200-4 7

Hung, T. N., Trung, N.D., \& Thach, N.N. (2019a). Beyond Traditional Probabilistic Methods in Econometrics. In: Kreinovich V., Thach N., Trung N., Van Thanh D. (eds) Beyond Traditional Probabilistic Methods in Economics. ECONVN 2019. Studies in Computational Intelligence, vol 809. Springer, Cham. https://doi.org/10.1007/978-3-030-04200-4_1

Hung T. N., Sriboonchitta, S., \& Thach, N.N. (2019b). On Quantum Probability Calculus for Modeling Economic Decisions. In: Kreinovich V., Sriboonchitta S. (eds) Structural Changes and their Econometric Modeling. TES 2019. Studies in Computational Intelligence, 808. Springer, Cham, 18-34. https://doi.org/10.1007/978-3-030-04263-9 2

Ilaboya Ofuan, J. \& Ohiokha Izien. F. (2016). Firm Age, Size and Profitability Dynamics: A Test of Learning-by-doing and Structural Inertia Hypotheses. Business and Management Research, 5(1), 28-39.

John, A. O., \& Adebayo, O. (2013). Effect of firm size on profitability: Evidence from Nigerian manufacturing sector. Prime Journal of Business Administration and Management (BAM), 3(9), 1171-1175.

Karabarbounis, L., \& Neiman, B. (2014). The Global Decline of the Labor Share. The Quarterly Journal of Economics, 129, 61-103. DOI:10.1093/qje/qjt032.

Killingsworth, M. R. (1982). "Learning by doing" and "investment in training": A synthesis of two "rival" models of the life cycle. The Review of Economic Studies, 49(2), 263-271.

Korner-Nievergelt, F. Roth, T., Felten, S., Guélat, J., Almasi, B., \& Korner-Nievergelt, P. (2015). Bayesian data analysis in ecology using linear models with $R, B U G S$ and STAN. Academic Press. 
Kreinovich, V., Thach, N.N., Trung, N.D., \& Thanh, D.V., eds. (2019). Beyond Traditional Probabilistic Methods in Economics. Cham: Springer, DOI: 10.1007/978-3-030-04200-4

Kristiansen, S., Furuholt, B., \& Wahid, F. (2003). Internet cafe entrepreneurs: pioneers in information dissemination in Indonesia. The International Journal of Entrepreneurship and Innovation, 4(4), 251-263

Kruschke, J. K. (2010). Doing Bayesian data analysis: a tutorial with R and BUGS, 1st edn. Academic Press.

Lazonick, W., \& Brush, T. (1985). The «Horndal Effect» in early U.S. manufacturing. Explorations in Economic History, 22(1), 53-96.

Lieberman, M. B. (1984). The learning curve and pricing in the chemical processing industries. The RAND Journal of Economics, 15(2), 213-228.

Lemoine, N.P. (2019). Moving beyond noninformative priors: why and how to choose weakly informative priors in Bayesian analyses. Oikos, 128, 912-928.

Majumdar, S. K. (1997). Impact of size and age on firm-level performance: Some evidence from India. Review of Industrial Organisation, 12, 231-241. http://dx.doi.org/10.1023/A:1007766324749

Montgomery, F. J. (1943). Increased Productivity in the Construction of Liberty Vessels. Monthly Labor Review, 57, 861-64.

Nezlek, J. B. (2008). An Introduction to Multilevel Modeling for Social and Personality Psychology. Social and Personality Psychology Compass, 2, 842-60. DOI:10.1111/j.1751-9004.2007.00059.x.

Okunbo O. \& Oghuvwu M. E. (2019). Firm size, age, and entrepreneurial performance. Accounting and Taxation Review, 3(2), $49-56$

Papatogonas, E. M. (2007). Financial performance of large and small firms: Evidence from Greece. International Journal of Financial Service Management, 2(1/2), 14-20. http://dx.doi.org/10.1504/IJFSM.2007.011668

Pervan, M., Pervan, I., \& Curak, M. (2017). The influence of age on firm performance: evidence from the Croatian food industry. Journal of Eastern Europe Research in Business and Economics, 2017(1), 1-10.

Prescott, E. C., \& Visscher, M. (1980). Organization capital. Journal of Political Economy, 88(3), 446-461.

Preston, L. E., \& Keachie, E. C. (1964). Cost functions and progress functions: An integration. The American Economic Review, 54(2), 100-107.

Rapping, L. (1965). Learning and World War II production functions. The Review of Economics and Statistics, 47, 81-86.

Roberts, G. O., \& Rosenthal, J. S. (2001). Optimal scaling for various Metropolis-Hastings algorithms. Statistical science, 16(4), 351-367.

Rosli, M. M. (2011). Determinants of small and medium enterprises performance in the Malaysian auto-parts industry. African Journal of Business Management, 5(20), 8235-8341.

Sriboonchitta, S., Nguyen, H. T., Kosheleva, O., Kreinovich, V., \& Nguyen, T. N. (2019, January). Quantum approach explains the need for expert knowledge: on the example of econometrics. In International Conference of the Thailand Econometrics Society (pp. 191-199). Springer, Cham.

Sheshinski, E. (1967). Tests of the" learning by doing" hypothesis. The review of Economics and Statistics, 49(4), 568-578.

Svítek, M., Kosheleva, O., Kreinovich, V., \& Nguyen, T. N. (2019, January). Why quantum (wave probability) models are a good description of many non-quantum complex systems, and how to go beyond quantum models. In International Econometric Conference of Vietnam (pp. 168-175). Springer, Cham.

Thach, N. N. (2020a). How to Explain when the ES is Lower than One? A Bayesian Nonlinear Mixed-Effects Approach. Journal of Risk and Financial Management, 13(2). https://doi.org/10.3390/jrfm13020021

Thach, N.N. (2020b). The Variable Elasticity of Substitution Function and Endogenous Growth; An Empirical Evidence from Vietnam. International Journal of Economics and Business Administration, 8(1), 263-277. DOI: 10.35808/ijeba/424

Thach, N.N., Kreinovich, V., \& Trung, N.D., eds. (2020). Data Science for Financial Econometrics. Cham: Springer.

Tomer, J. (1981). Organizational change, organization capital and economic growth. Eastern Economic Journal, 7(1), 1-14.

Vietnam General Statistics Office (2019). https://gso.gov.vn/default.aspx?tabid=716

Wright, T. P. (1936). Factors affecting the cost of airplanes. Journal of the Aeronautical Sciences, 3(4), 122-128.

Yang, R., \& Berger, J. O. (1996). A catalog of noninformative priors (pp. 97-42). Institute of Statistics and Decision Sciences, Duke University.

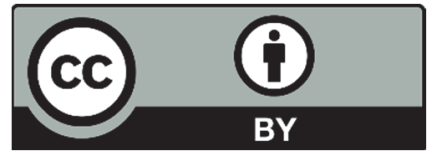

(C) 2020 by the authors; licensee Growing Science, Canada. This is an open access article distributed under the terms and conditions of the Creative Commons Attribution (CC-BY) license (http://creativecommons.org/licenses/by/4.0/). 